Proceedings

\title{
An outline for Designing Socio-Environmental transitions for In-between Territories of the Greater Bay Area.
}

\author{
Dan Narita, Ph.D. 1 \\ 1 Affiliation: Independent Scholar; Dan.Narita@aalumni.org \\ * Correspondence: Dan.Narita@aalumni.org
}

\begin{abstract}
:
Ground-up socio-environmental approaches to Regional planning prioritising nature-based and human settlements at the local scale are examined. The research aims to rethink an expanded critical infrastructure framework for the Greater Bay Area (GBA) in China, taking social and eco-system service resilience into account. The spaces studied are In-between Territories engulfing the main 9+2 cities forming the GBA transactional network of cities. An alternative approach to design thinking seeks to transform In-between Territories as the critical infrastructure and the backbone resource of a world-class urban agglomeration. Based on research by design projects, the research sets out to redefine the types of critical infrastructures and livelihood adaptations needed when restoring after catastrophic events, social welfare deprivation and digital divide challenges in communities.
\end{abstract}

Keywords: Critical Infrastructure, Nature-based Regional Design, Greater Bay Area, Green Growth.

Citation: Narita, D., 2022, Designing Nature-based Transitions for In-between Territories in the Greater Bay Area. SUPTM 2022 conference proceedings sciforum-052063. https://doi.org/10.31428/10317/10587

Publisher's Note: UPCT and Sciforum stays neutral with regard to jurisdictional claims in published maps and institutional affiliations.

Copyright: (c) 2022 by the authors. Submitted for possible open access publication under the terms and conditions of the Creative Commons Attribution (CC BY) license (https://creativecommons.org/license s/by/4.0/).

\section{Introduction}

While not fully embraced in mainstream urban planning practices, the uptake of nature-based urban design and ecology-driven urbanization is increasingly emerging in the planning and design disciplines. New approaches to regional planning that prioritize the well-being of people and the livability of settlements at the local scale are treated.

Formulating future-proof design and planning strategies at the regional scale necessitates the inclusion of the In-between Territories binding together high-density and dispersed cities in mega-city clusters. With an emphasis on research by design methodology, the aim is to rethink a Critical Infrastructure Design Framework for the Greater Bay Area (GBA) in Guangdong Province, China. Furthermore, the implementation of nature-based solutions to achieve sustainable urbanization while supporting economic growth and developing livable cities for environmental and human well-being in the Greater Bay Area is discussed.

The research studies the livelihoods of local people in poverty-stricken communities in the upstream region of the Dongjiang River Basin (DRB). The DRB is a strategically important water supply and hydrological asset for the Greater Bay Area (GBA). Nevertheless, the living conditions of people in settlements at the water supply reservoirs are under-researched. The case study sites of the research are approximately $600 \mathrm{~km}$ away 
from the wealthier cities of the GBA, including Guangzhou, Shenzhen, Hong Kong and Macau, located in the downstream region of the river basin. Opportunities for proposing an alternative, people-oriented urbanity is explored. Alternative design approaches propose to re-integrate, re-nature and protect In-between Territories as the Critical Infrastructure and the backbone resource of a world-class urban agglomeration.

\section{The Problem}

In-between Territories play a critical role in the survival of regional-scale ecological cohesion. In a catastrophic event, polycentric regional structures and city cluster networks would compromise the system resilience without the in-between territories engulfing metropolitan areas. The eco-system services and diffused settlement structures (Indovina, Matassoni, et Savino, 1990) cater for the capacity to absorb acute and slow-burning stresses (Rodin, Maxwell, 2014) in densely populated cities. The spaces in-between metropolitan areas can manifest hybrid urban-rural characteristics and fragmented land-use mosaics. Some of the characteristics of dispersed settlements could be scattered industrial land uses combined with farming plots (Vigano, Cavalieri, et Corte, 2018). Other peripheral territories could be described as spaces of extractions (Arboleda, 2020) - subjected to either legal or illegal natural resource exploitation. Often neglected are the peripheral communities living at engineered-grey critical infrastructure projects, such as water reservoirs or nature reserves of recreational, tourism, biodiversity habitat and scientific value. Despite providing vital resources to wealthy command centers of global city networks (Sassen, 2013), remote settlements are poverty-stricken, lack the access to know-how and financial resources to tackle environmental challenges for the evolution into human livable cities. For example, in the case of water extraction, developed city clusters are primarily concerned about securing the water supply to urban centers. Hardly any attention is paid to protecting safe drinking water for the local communities living at water supply infrastructures.

Rural areas and villages impacted by industrial water, soil and air pollution have been described as 'cancer villages' (Chen, Cheng, et Luo, 2020). Since approx. 2006 the Chinese media began to increasingly report on the high cancer mortality rate in rural areas infested by industrial waste and toxic chemicals contamination (Liu, 2010). Other phenomena are the emergence of the so-called 'Taobao villages', which developed as the rural bricks-and-mortar infrastructure of Chinese online retaining expanding its presence in peri-urban and remote territories. The planning and upgrading of the Chinese high-speed and rail network involve implementing TOD and satellite towns, business districts and housing estates as landscapes for rent extraction (Rolnik, 2019). As a result of the infrastructure and urbanization corridor developments, the territories between metropolitan areas became either fragmented land or led to dysfunctional eco-system services. Additionally, social networks, community fragmentation and the breakdown of family structures have severe consequences in in-between territories considering employment-seeking family members migrating to cities and leaving elderly, children and vulnerable members of society.

\section{Objectives - Rebuilding \& Growing Back Better}

To rebuild back better resilience $(\mathrm{OECD}, 2020)$ in both the mega-city networks and its in-between territories, a rethinking of what critical infrastructures encompass to safeguard regional-scale coherence and sustainable evolution of cities is pertinent. At the heart of the mission (Mazzucato, 2021) to re-design the habitats for humans and biodi- 
versity lies the objective to first and foremost reinstate landscapes that nurture life (Rolnik, 2019) instead of short-term economic gains.

Mitigation strategies for environmental disasters are engineered canals, belowground pipes, water reservoirs, water filtration plants, concrete sea walls, retaining and dams. Such grey infrastructure types remain critical infrastructure provisions for flood risk management, avalanches, mud and landslides, and drought (Sebesvari, Woelki, Walz, Sudmeier-Rieux, Sandholz, Tol, García, Blackwood, et Renaud, 2019). The pitfall of grey infrastructures is the static nature of the infrastructure with limited possibilities to adapt to unexpected environmental disruptions and society's perpetually adapting needs. By reconsidering the basic types such as Blue, Green and Grey critical infrastructures, other safety measures such as welfare spaces as social infrastructures (Munarin et Tosi, 2014) are associated provisions. Not limited to the essential provisions of healthcare and educational facilities, libraries, affordable housing, and elderly care homes are institutions that support synergistic, caring, and collaborative community initiatives to be formed. As part of design processes, the concept of Critical Infrastructure is widened to include all the disaster prevention measures needed to preserve life, justice, empathy for human beings, and biodiversity.

\section{Methodology:}

Research by design studies underpin the research in alternative livelihood strategies for disadvantaged communities. The design approach aims at utilizing projects as a knowledge producer. Scenarios for a nature-based and socially-inclusive transformation of distressed settlements are proposed with design interventions for the case study sites. The analytical and information gathering phase is structured in four scales: Scale one is the Greater Bay Area regional analysis and, followed by scale two, the Dongiiang River Basin territory. The macro-scale studies involve cartographic analysis and mapping exercises, emphasizing the hydrological water supply network and revealing the system of resource extraction. River basin planning schemes are proposed to address issues such as farmland preservation, constraining the expansion of urban development, planning for low-density settlement structures, and preserving nature reserves. At the third scale, three $50 \times 50 \mathrm{~km}$ case study sites are analyzed utilizing mapping, photographic surveys and the transect as an analytical and design method to understand the territories in terms of their natural capital, environmental issues and local livelihood ecologies. The fourth scale investigations engage with the communities at the water reservoirs. Extensive fieldwork, structured interviews with local inhabitants are conducted to understand the environmental and social struggles in the disadvantaged settlement. The interactions with local people provide insights into their livelihood strategies, a better understanding of their needs, and possible interventions to transform their compromised circumstances.

\section{Results:}

Alternative micro-economic livelihood scenarios have been constructed based on fieldwork research and collaboration with five local people. While respecting their living environments, examples of possible livelihood diversification are put forward. By acquiring new skills and know-how, some individuals contribute to sustainability education and adaptation to renewable energy sources in their community. Other characters set up organic farming, agro-tourism and specialize in local food produce, contributing to their income diversification. Examples that are assisted by recent technological innovations are online retailing activities and drone delivery services for remote regions. All the scenarios constructed represent bottom-up community-based initiatives to promote local 
resilience and green economic growth. Repertoires for self-perpetuating economic activities are exemplified to provide adaptation options and possibilities to better rebound from an unexpected crisis. Civil society organizations supported by environmental and social welfare infrastructures are embedded in the settlements to transition to the long-term independent development of local alternative urbanities.

\section{Preliminary Recommendations}

Nature-based regional design and people-centered planning responsive to new environmental and societal challenges inevitably formulate new urban questions (Secchi, 2013). As a consequence of identifying emerging urban phenomena, people's needs and systemic crises lead to perpetual adaptations and the re-designing of critical infrastructures. For instance, questioning our development patterns and curbing the overconsumption of natural resources goes hand in hand with preserving the environmental carrying capacities at the Greater Bay Area $(\mathrm{Wu}, \mathrm{Wu}$, et Zang, 2021) for future generations. Further, maintaining spare capacities in the natural environment and human communities to restore eco-system functions and livelihoods following a shock or catastrophic event can only be achieved by designing In-between territories with the same care, state of the art knowledge and innovation, as developed internationalized metropolitan centers.

Funding: This research received no external funding.

Conflicts of Interest: The author declares no conflict of interest.

\section{References}

1. Arboleda, M., (2020). Planetary mine: Territories of extraction under late capitalism. Verso Trade.

2. Chen, A., Cheng, P. and Luo, Y., (2020). Chinese" Cancer Villages". Amsterdam University Press.

3. Greater Bay Area, (2018), "Outline Development Plan for the Guangdong-Hong Kong-Macao Greater Bay Area", https://www.bayarea.gov.hk/filemanager/en/share/pdf/Outline_Development_Plan.pdf, Accessed 13 April 2020.

4. Indovina, F., Matassoni, F.R.A.N.C.A. and Savino, M., (1990). La città diffusa (pp. 19-43). Venecia: Daest.

5. Liu, L., (2010). Made in China: cancer villages. Environment: Science and Policy for Sustainable Development, 52(2), pp.8-21.

6. Mazzucato, M., (2021). Mission economy: A moonshot guide to changing capitalism. Penguin UK.

7. Munarin, S. and Tosi, M.C., (2014). Welfare space. On the role of Welfare State Policies in the construction of the contemporary City, List, Milano.

8. Narita, D. (2021), Emancipatory Urbanization. On the Independence of Mountain Territories in relation to Mega - City clusters: A Transect Approach, Cuvillier Publisher, Göttingen.

9. OECD, (2020), " Building back better: A sustainable, resilient recovery after COVID-19",

10. https://www.oecd.org/coronavirus/policy-responses/building-back-better-a-sustainable-resilient-recovery-after-covid-19-52b8 69f5/, June 272021.

11. Rodin, J. and Maxwell, C., (2014). The resilience dividend. Profile Books.

12. Rolnik, R.,(2019). Urban Warfare. Verso Trade.

13. Sassen, S., (2013). The global city. Princeton University Press.

14. Sebesvari, Z., Woelki, J., Walz, Y., Sudmeier-Rieux, K., Sandholz, S., Tol, S., García, V.R., Blackwood, K. and Renaud, F.G., (2019). Opportunities for considering green infrastructure and ecosystems in the Sendai Framework Monitor. Progress in Disaster Science, 2, p.100021.

15. Secchi B (2013) La città dei ricchi e la città dei poveri. Laterza eds, Roma.

16. Viganò, P., Cavalieri, C. and Corte, M.B. eds., (2018). The horizontal metropolis between urbanism and urbanization (ISBN 978-3-319-75974-6). Springer.

17. Wu, M., Wu, J. and Zang, C., (2021). A comprehensive evaluation of the eco-carrying capacity and green economy in the Guangdong-Hong Kong-Macao Greater Bay Area, China. Journal of Cleaner Production, 281, p.124945. 